\title{
TRAMADOL VERSUS FENTANYL INFUSION DURING ANAESTHESIA; HAEMODYNAMIC EFFECTS, POSTOPERATIVE ANALGESIA AND OUTCOME
}

\author{
By \\ Atef D. Demian (MD), Ashraf M. Wahba (MD), \\ Samy H.M. Hussein (MD) and Hussein M.M. A: ' , $_{\mathrm{i}} \mathrm{C}$ )
}

From
Department of Anaesthesia, Mansoura University.

\section{ABSTRACT}

This prospective randomized study compared I.V. infusion of tramadol "T" with fentanyl " $F$ " for analgesia and postoperative outcome in 30 patients undergoing major abdominal surgery. A balanced general anaesthetic technique was given to both groups. In " $T$ " group ( $n=15)$, tramadol (1mg.kg-1) was given firstly then infusion started as follow: $1 \mathrm{st} \mathrm{hr:} 1 \mathrm{mg} \cdot \mathrm{kg}-1 . \mathrm{hr}-1$, 2nd hr.: $0.75 \mathrm{mg} \cdot \mathrm{kg}^{-1} \cdot \mathrm{hr}^{-1}$ and $0.5 \mathrm{mg} . \mathrm{kg}-$ 1. $\mathrm{hr}^{-1}$ for the following hours. In " $\mathrm{F"}$ group $(n=15)$, Fentanyl $\left(1.5 \mu \mathrm{g} / \mathrm{kg}^{-1}\right)$ was given firstly then infusion was given in the following regimen: $1 \mathrm{st} \mathrm{hr}$ : $1 \mu \mathrm{g} . \mathrm{kg}^{-1} \cdot \mathrm{hr}^{-1}$, 2nd hr.: $0.75 \mu . \mathrm{kg}^{-1} \mathrm{hr}^{-1}$ and $0.5 \mu \mathrm{g} . \mathrm{kg}^{-1}$,.hr-1 for the following hours. Infusion stopped at time of closure in both groups. No significant haemodynamic differences were detected between both groups. The early postoperative gasometric readings were within acceptable values in both groups. Mean VPS ranged from 0.47 \pm 0.9 to $1.2 \pm 0.4$ and from $0.73 \pm 0.3$ to $1.33 \pm 0.5$ in " $T$ " and " $F$ " groups respectively in the first 6 hours postoperatively. VPS showed no significant differences between both groups. It increased significantly as related to basal value after 5 and 4 hours in " $T$ " and " $F$ " groups respectively. We concluded that tramadol given by I.V. infusion appears to be a promising analgesic with respiratory and haemodynamic stability.

\section{INTRODUCTION}

In the last few years, many serious attempts have been tried to manage postoperative pain. Opioids and non-steroidal anti-inflammatory drugs have been the corner-stone of pain management. Respiratory depression represents the most dreadful side MANSOURA MEDICAL JOURNAL 


\section{6 \\ TRAMADOL VERSUS FENTANYL INFUSION DURING etc...}

effects of opioid analgesia(1). In the last 2 decades, new drugs have been applied in clinical practice for management of postoperative pain.

Tramadol hydrochloride is a centrally acting synthetic analgesic. Its effect is mediated via: week opioid $\mu$ agonist action and non-opioid action i.e. enhancement of monoaminergic descending inhibitory spinal transmission (2). It has been studied extensively for management of postoperative pain by either I.V. bolus dose(3) or by infusion(4). The drug was compared with pethidine(5) and fentanyl(6) for analgesic potency and respiratory depressant effects. Tramadol proved to be different from other opioids in its side effects profile, with little cardiovascular and respiratory depression, as well as low dependency potential $(7,8,9)$.

More evaluation of the optimal dosage and best route of administration of tramadol is needed. This study was designed to test the hypothesis that analgesic effect of tramadol-given by intravenous iniusion intraoperativly-can continue on the post-operative period without haemodynamic or respiratory complications. This effect was compared with that of a popular, short acting opioid agonist analgesic i.e. fentanyl.

\section{PATIENTS AND METHODS}

This prospective randomized, single center study was conducted on thirty patients (ASA I \& II) of either sex, scheduled for major elective abdominal surgery in Gastroenterology Center, Mansoura University. The age of patients ranged from 20 to 60 years. Patients having pain syndrome or receiving regular analgesics before the operation were excluded from the study. The protocol was approved by the Research Ethical Committee of Mansoura University.

Preoperative assessment included medical history, clinical examination, chest X-ray, ECG and complete laboratory investigations. Premedication was done by $5 \mathrm{mg}$ diazepam orally on the night before operation and the same dose was repeated on the morning of surgery. On arrival to the theatre, basal readings of $H R$, MBP and blood gasometry were recorded.

According to the type of analgesic given, patients were randomized into 2 groups: group $1(n=15)$ received

Vol. 32, No. 1 \& 2 Jan. \& April, 2001 
Tramadol "T" and group $2(n=15)$ received fentanyl " $F$ ". The randomization list was computer generated. In "T" group, atropine was given $(0.005$ mg.kg-1), then anaesthesia was induced by midazolam (0.1 mg. $\mathrm{kg}^{-1}$ ), tramadol (1 $\left.\mathrm{mg} \cdot \mathrm{kg}^{-1}\right)$ and thiopentone (5 mg. $\mathrm{kg}^{-1}$ ). Suxamethonium (1 $\mathrm{mg} \cdot \mathrm{kg}^{-1}$ ) was given for facilitation of endotracheal intubation. Tramadol infusion was started at time of induction and the rate was adjusted as follows: first hour: $1 \mathrm{mg} \cdot \mathrm{kg}^{-1} \cdot \mathrm{hr}^{-1}$., second hour: $0.75 \mathrm{mg} \cdot \mathrm{kg}^{-1} \cdot \mathrm{hr}^{-1}$ and the following hours: $0.5 \mathrm{mg} \cdot \mathrm{kg} .{ }^{-1} \mathrm{hr}^{-1}$; then infusion stopped at time of peritoneal closure. Maintenance of anaesthesia was done by $\mathrm{N}_{2} \mathrm{O}: \mathrm{O}_{2}\left(\mathrm{FIO}_{2}=0.4\right)$, halothane $(0.2-0.8 \%)$ and atracurium (0.5 mg.kg-1 initially, followed by incremental doses of $0.1 \mathrm{mg} \cdot \mathrm{kg}^{-1}$ ). Reversal of neuromuscular blockade was done by prostigmine (0.04 mg.kg-1) and atropine $(0.02$ $\mathrm{mg} \cdot \mathrm{kg}^{-1}$ ).

In the fentanyl group "F", the same anaesthetic technique was followed except that fentanyl bolus $(1.5 \mu \mathrm{g} . \mathrm{kg}-1)$ was given at time of induction, then fentanyl infusion was given in the following regimen: 1 st hour: $1 \mu \mathrm{g} . \mathrm{kg}^{-1}$. $\mathrm{hr}^{-1}$, 2nd hour : 0.75 $\mathrm{Mg} \cdot \mathrm{kg}^{-1} \cdot \mathrm{hr}-1$ and the following hours:
$0.5 \mu \mathrm{g} \cdot \mathrm{kg}^{-1} \cdot \mathrm{hr}^{-1}$

Patients were monitored by 5 leads ECG, non-invasive arterial blood pressure, pulse oximetry and capnography. The haemodynamic data (HR and MBP) were recorded $15,30,60,120 \mathrm{~min}$. after induction, at recovery and $30,60,120 \mathrm{~min}$ afte recovery. Blood gasometric data $\left(\mathrm{PaO}_{2}\right.$, $\mathrm{SaO}_{2}, \mathrm{pH}, \mathrm{PaCO}_{2}, \mathrm{HCO}{ }_{3}$ ) were recorded preoperatively, one hour after induction and one hour postoperatively (on room air).

Postoperative pain was assessed using verbal pain score "VPS"(10) every 1 hour till 6 hours postoperatively as follow: "O" = No pain at rest or movement, " $1 "$ = No pain at rest, slight pain on movement; " 2 " = Intermittent pain at rest. moderate pain on movement; " 3 " = continuous pain at rest, severe pain on movement. This assessment was done by an independent observer who was blinded to the type of analgesic used. Any postoperative complications e.g. nausea, itching and respiratory depression were recorded. Additional doses of the same analgesic (Tramadol $0.5 \mu \mathrm{g} \cdot \mathrm{kg}^{-1}$ or fentanyl $0.5 \mu \mathrm{g} \cdot \mathrm{kg}^{-1}$ ) were given if VPS reached 2 in the postoperative period. 


\section{STATISTICAL ANALYSIS}

Analysis of variance (ANOVA two ways test) was used for the parameteric values and Tukey (HSD) was used for comparison of means. A non-parameteric Kolomgrov-Simirnov test and Wilcoxon matched pairs test was used for VPS values. The level of significance was considered when $P$ value $<0.05$.

\section{RESULTS}

The demographic and clinical data (table 1) demonstrated no significant changes between the two groups. The preoperative haemodynamic values were within accepted levels. Comparing both groups, haemodynamic variables did not show significant differences during intra-and postoperative periods. Fentanyl group " $F$ " showed significant decrease in HR and MBP $30,60 \mathrm{~min}$. and $30,60,120$ min. respectively after start of fentanyl infusion when compared with the basal values (Table 2).

Blood gasometric values showed no significant changes between both groups (Table 3). Intraoperatively, $\mathrm{PaO}_{2}$ in both groups were significantly higher than basal readings with the increased $\mathrm{FIO}_{2} . \mathrm{PaCO}_{2}$ in "T" group was significantly low compared with the basal value. The early postoperative gasometric readings were within acceptable values in both groups (Table 3).

Verbal pain score (VPS) showed no significant differences between both groups in the first 6 postoperative hours. However, significant increases in VPS-compared with first hour reading-were recorded in the fifth and fourth hours in " $T$ " and " $F$ " groups respectively (Fig. "1"). Pain free patients (VPS=0)-one hour postoperatively-were $73.3 \%$ and $66.6 \%$ in " $T$ " and " $F$ " groups respectively and these ratios decreased until reached $20 \%$ and $6.7 \%$ in " $T$ " and " $F$ " groups respectively after 3 hours (Table 4). Only one case in " $T$ " group showed complete failure of analgesia (VPS = 3 on recovery). Patients that needed analgesics (VPS $\geq 2$ ) were $46.7 \%$ and $40 \%$ in " $T$ " and " $F$ " groups respectively. Nausea and vomiting couldn't be evaluated because of presence of Ryle's tube. No signs of respiratory depression were recorded in " $T$ " group as evidenced by normal $\mathrm{PaCO}_{2}$ (Table 3 ) and normal respiratory rate (Table 4). Only one case in " $F$ " group showed a respiratory rate of $10 / \mathrm{min}$. for $15 \mathrm{~min}$. after recovery but with accepted blood gasometric variables. 
Table (1): Demographic and clinical data of the studied patints. Values are number or mean $\pm \mathrm{SD}$ (range)

\begin{tabular}{|l|c|c|}
\hline & $\begin{array}{c}\text { Tramadol group "T" } \\
(\mathbf{n}=15)\end{array}$ & $\begin{array}{c}\text { Fentanyl group "F" } \\
(\mathbf{n}=15)\end{array}$ \\
\hline Age (Yr) & $45.5 \pm 13$ & $46.8 \pm 12$ \\
Sex (M/F) & $(24-58)$ & $(31-59)$ \\
Weight (Kg) & $10 / 5$ & $8 / 7$ \\
& $70.0 \pm 11$ & $67.7 \pm 12$ \\
Surgery time (min.) & $(54-100)$ & $(55-90)$ \\
& $177 \pm 31$ & $162 \pm 28$ \\
Type of surgery: & $(120-280)$ & $(130-240)$ \\
- Colorectal cancer & & 5 \\
- Gastric oper. & 6 & 3 \\
- Biliary surgery & 4 & - \\
- Malignant Int. obst & 1 & - \\
- Ulcerative colitis & 1 & 1 \\
- Pseudopancreatic cyst & 1 & \\
\hline
\end{tabular}

Table (2): Heart rate (HR) and mean arterial blood pressure (MBP) in Tramadol " $T$ " and Fentanyl " $F$ " groups. Values are mean \pm SD.

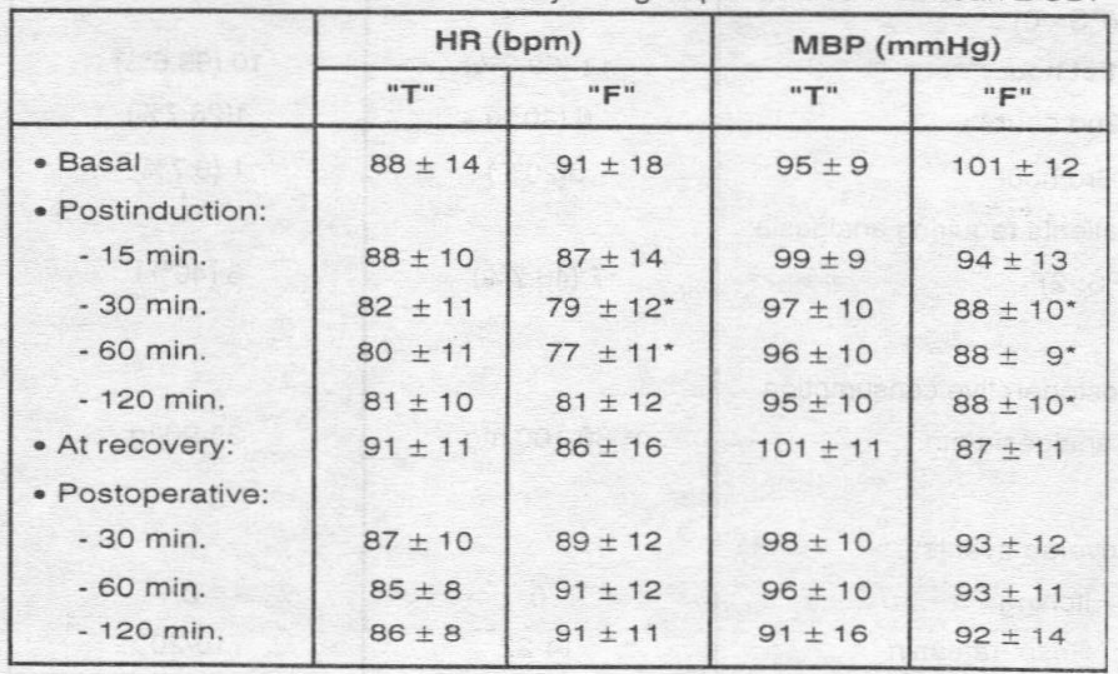

- Significant changes as compared with the basal value $(P<0.05)$ 
390 TRAMADOL VERSUS FENTANYL INFUSION DURING etc...

Table (3) : Blood gasometric variables of Tramadol "T" and Fentanyl "F" groups. Values are mean \pm SD.

\begin{tabular}{|c|c|c|c|c|c|c|c|c|c|c|}
\hline & \multicolumn{2}{|c|}{$\mathrm{PaO}_{2}(\mathrm{mmHg})$} & \multicolumn{2}{|c|}{$\mathrm{SaO}_{2}(\%)$} & \multicolumn{2}{|c|}{$\mathrm{pH}$} & \multicolumn{2}{|c|}{$\begin{array}{l}\mathrm{PaCO}_{2} \\
(\mathrm{mmHg})\end{array}$} & \multicolumn{2}{|c|}{$\begin{array}{c}\mathrm{HCO}_{3}^{-} \\
\left(\mathrm{mmol} . \mathrm{L}^{-1}\right)\end{array}$} \\
\hline & $" T "$ & "F" & "T" & "F" & $" \mathrm{~T} "$ & "F" & "T" & "F" & "T" & "F" \\
\hline \multirow[t]{2}{*}{ Preoperative } & 97.2 & 96.2 & 95.4 & 96.3 & 7.41 & 7.39 & 39.9 & 40.0 & 22.8 & 22.3 \\
\hline & \pm 5 & \pm 7 & \pm 2 & \pm 2 & \pm 0.1 & \pm 0.1 & \pm 4 & \pm 4 & \pm 2 & \pm 2 \\
\hline \multirow[t]{2}{*}{ 1hr. postinduction } & $187.1^{*}$ & $170.5^{*}$ & 97.7 & 98.2 & 7.39 & 7.38 & $34.8^{*}$ & 37.7 & 21.9 & 21.1 \\
\hline & \pm 21 & \pm 25 & \pm 1 & \pm 1 & \pm 0.1 & \pm 0.1 & \pm 2 & \pm 3 & \pm 2 & \pm 2 \\
\hline \multirow[t]{2}{*}{ 1hr. postoperative } & 92.4 & 89.1 & 94.9 & 95.3 & 7.39 & 7.37 & 39.0 & 42.8 & 21.7 & 21.8 \\
\hline & \pm 7 & \pm 7 & \pm 2 & \pm 1 & \pm 0.04 & \pm 0.03 & \pm 5 & \pm 4 & \pm 2 & \pm 2 \\
\hline
\end{tabular}

* Significant changes as compared with the basal value $(P<0.05)$

Table (4): Postoperative outcome in Tramadol " $T$ " and Fentanyl " $F$ " groups. Values are number, range or (percentage)

\begin{tabular}{|l|c|c|}
\hline & Tramadol "T" & Fentanyl "F" \\
\hline - Pain free patients: & & \\
(VPS=0) & $11(73.3 \%)$ & $10(66.6 \%)$ \\
1 st hour : & $6(40 \%)$ & $4(26.7 \%)$ \\
2nd hour: & $3(20 \%)$ & $1(6.7 \%)$ \\
3rd hour: & & $6(40 \%)$ \\
- Patients requiring analgesia: & $7(46.7 \%)$ & \\
(VPS>2) & & $35-90 \mu \mathrm{g}$ \\
- Postoperative consumption & & \\
of analgesia/ptn. & $30-100 \mathrm{mg}$ & $10-20$ \\
\hline
\end{tabular}

Vol. 32 , No. 1 \& 2 Jan. \& April, 2001 


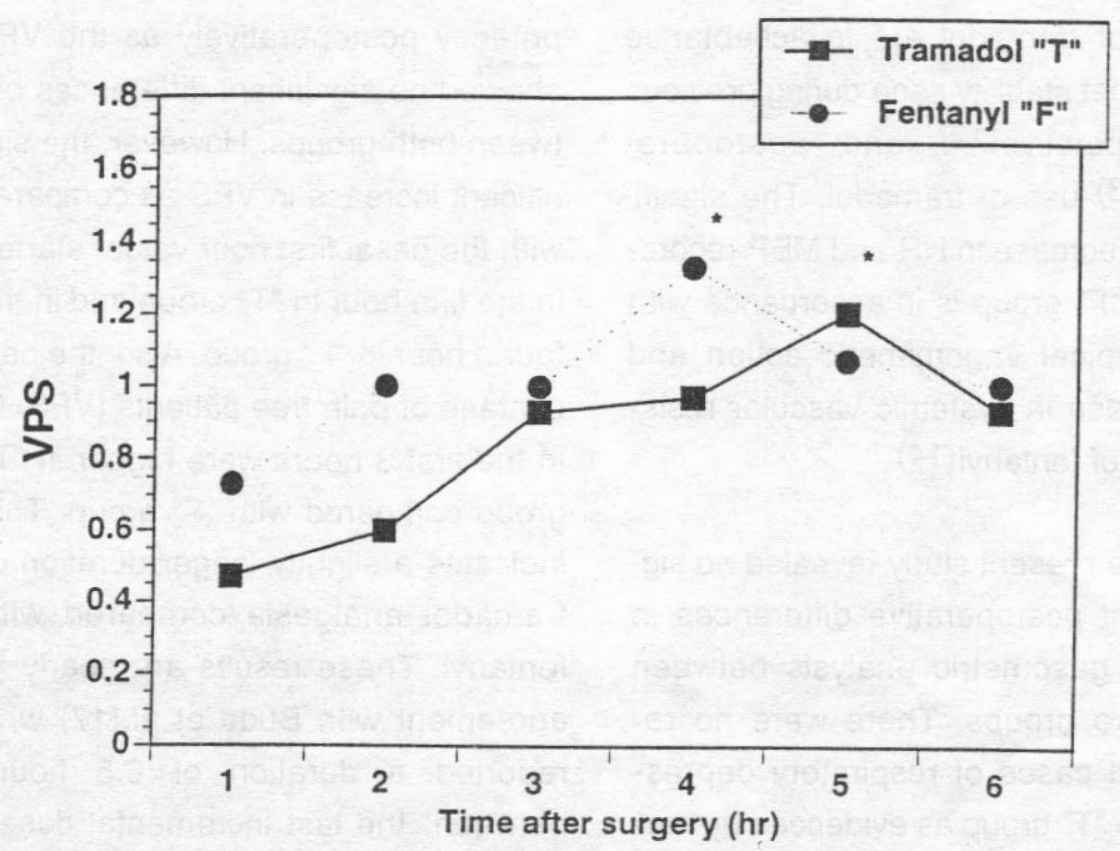

Fig. (1) : The mean verbal pain score (VPS) in Tramadol "T" and Fentanyl " $F$ " groups during postoperative period.

* Sig. change as compared with basal value in each group $(P<0.05)$.

\section{DISCUSSION}

The present report shows that I.V. infusion of either tramadol or fentanyl can provide adequate intraoperative analgesic supplementation and-to some extent-considerable postoperative analgesia in patients undergoing major abdominal surgery. Also, the incidence of complications was nearly abscent in both groups.

It has been suggested that tramadol, $\mathrm{N}_{2} \mathrm{O}$, enflurane anaesthesia lead to $65 \%$ incidence of awareness (4).
However, a recent report(11) found that tramadol in doses up to $200 \mathrm{mg}$ during stable light $\mathrm{N}_{2} \mathrm{O}$-isoflurane anaesthesia did not lead to clinically significant lightening of anaesthesia. Although we did not assess the level of awareness during general anaesthesia with both groups, we think that the used regimen was enough to suppress awareness as evidenced by stable haemodynamic parameters, no need for further bolus doses of analgesics or to increase concentration of halothane. The haemodynamic find- 


\section{TRAMADOL VERSUS FENTANYL INFUSION DURING etc...}

ings of tramadol are in acceptance with that stability seen during previous intraoperative(12) and postoperative(13) use of tramadol. The significant decrease in HR and MBP recorded in " $\mathrm{F}$ " group is in accordance with the typical vagomimetic action and decrease in systemic vascular resistance of fentanyl(14).

The present study revealed no significant postoperative differences in blood gasometric analysis between the two groups. There were no recorded cases of respiratory depression in " $T$ " group as evidenced by normal respiratory rate and $\mathrm{PaCO}_{2}$, a finding goes in parallel with the fact that tramadol has minimal(5) or even no respiratory depressant action(15). The dual mechanism of action is the accepted explanation for its negligable effect on respiration despite its analgesic potency $(16)$. Only one case in "F" group showed slow respiratory rate $(10 / \mathrm{min})$ after recovery but with acceptable blood gases values and without requirement of naloxone. This indicate that fentanyl also in the given regimen was a safe short acting analgesics.

The two comparable drugs in this study showed nearly equal analgesic potency postoperatively as the VPS showed no significant differences between both groups. However, the significant increase in VPS-as compared with the basal first hour value- started in the fifth hour in " $T$ " group and in the fourth hour in "F" group. Also, the percentage of pain free patients (VPS $=0$ ) in the first 3 hours were higher in " $T$ " group compared with " $F$ " group. This indicates a slightly longer duration of tramadol analgesia compared with fentanyl. These results are nearly in agreement with Budd et al.(17) who reported a duration of 6.5 hours between the last incremental doses of tramadol and time at which the patient required further analgesia. Moreover, James et al.(18) reported that a single I.V. dose of $150 \mathrm{mg}$ tramadol provided postoperative analgesia compared to that of epidural morphine in the early postoperative 6 hours.

It is clear that both analgesics-in the given regimen-have nearly the same potency with slightly longer duration of action of tramadol than fentanyl. Tramadol-given by the infusion technique-appears to be a promising drug for intra-and postoperative pain relief with respiratory and haemodynamic stability. 
REFERENCES

1- Bailey P, Stanley T, Pace N, Ashburn M, East K (1990) : Frequent hypoxemia and apnea after sedation with midazolam and fentanyl. Anesthesiology; 73 : 82630.

2- Dayer $P$, Desmeules $\mathrm{J}$ and Collart L (1997) : The pharmacology of tramadol. Drugs; $53: 18-24$.

3- DeWitte J, Rietman GW and Vandentrouke G (1998) : Postoperative effects of tramadol administered at wound closure. European $J$ of Anaesthesiology; 15 : 190195.

4- Lehmann KA, Horrichs G, Hoeckle W (1985) : Tramadol as an intraoperative analgesic. A randomized double blind study with placebo. Anaesthesist; 34 : 11-19.

5- Vickers MD, O'Flaherty D, Szekely SM, Read M and Yoshizumi J (1992) : Tramadol; pain relief by an opioid without depression of respira- tion. Anaesthesia; $47: 291$ 296.

6- Hackl W, Fitzal S and Lackner F (1986) : A comparison of fentanyl versus tramadol patient-controlled analgesia. Anaesthesist ; 35 : 365-371.

7- Houmes R-JM, Voets MA, Verkaaik A, Erdmann W, Lechmann B (1992) : Efficacy and safety of tramadol versus morphine for moderate and severe postoperative pain with special regard to respiratory depression. Anesth Analg; 74 : 510-514.

8- Paravicini D, Zander J, Hansen J (1982) : Effect of tramadol on haemodynamics and blood gases in the early postoperative period. Anaesthesist; 31 : 611-614.

9- Perston $\mathrm{Kl}$, Jasinski DR, testa M (1991) : Abuse potential and pharmacological comparison of tramadol and morphine. Drug Alcohol Depend; $27: 7-17$.

10- Espinet A, Henderson DJ and MANSOURA MEDICAL JOURNAL 
394 TRAMADOL VERSUS FENTANYL INFUSION DURING etc...

Does preincisional thoracic extradural block combined with declofenac reduce postoperative pain after abdominal hysterectomy?. $\mathrm{Br} \mathrm{J}$ Anaesth; $76:$ 209-213.

11- Goetzee JF, Martiz JS and Dutorr JC (1996) : Effect of tramadol on depth of anaesthesia. Br J Anaesth; 76 : 415-18.

12- Muller $H$, Stoyanov M, Brahler $A$ and Hempelmann $G$ (1982): Haemodynamic and respiratory effects of tramadol during nitrous oxideoxygen artificial respiration. Anaesthesist; 31 : 604-610.

13- Chrubasik J, Buzina M, Schutle MG and Alon E (1992) : Intravenous tramadol for postoperative pain, a comparison between intermittent dose regimen with and without maintenance infusion. European $\mathrm{J}$ of Anaesthesiology; $76: 415-418$.

14- Flacke J, Davis L, Flacke W et al. (1985) : Effect of fentanyl and diazepam in dogs deprived of autonomic tone. Anesth Analg: 64 : 10531059.

15- Tarkilla P, Tuominen $M$ and Lindgrenl (1998) : Comparison of respiratory effects of tramadol and pethidine. European $\mathrm{J}$ of Anaesthesiology; 15 : 6468.

16- Radbruch L, Grond S and Lehman KA (1996) : A riskbenefit assessment of tramadol in management of pain. Drug safety; $15: 8-29$.

17- Budd K, Fenn GC, Moynihan J. et al. (1996) : Intravenous tramadol in the treatment of acute postoperative pain : a dose response study. Modern Medicine; 13 : 44-46.

18- James MFM, Heizke SAM and Gordon PG (1996) : Intravenous tramadol versus epidural morphine for postoperative pain relief-a placebocontrolled double blind study. Anesth Analg; 83 : 87-91. 


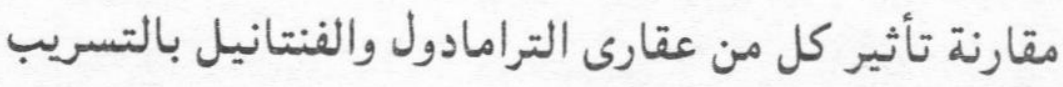

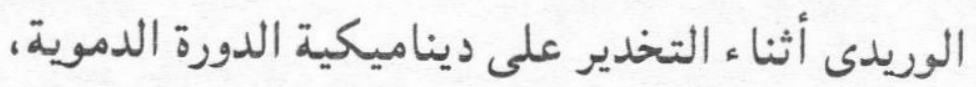 تسكين الألم، وحاله المريض بعد العملية}

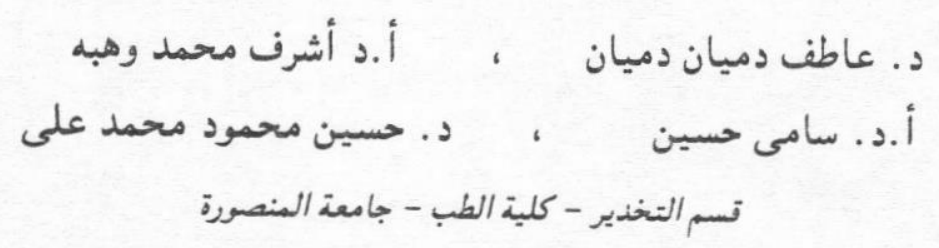

أجريت هذه الدراسة العشـوائية لتقارن بين عقارى الترامادول والفنتـانيل عند إستخدامها بطريقة التسريب الوريدى من حيث درجة التسكين وحاله المريض بعد العملية. وشملت هذه الدراسة ثلاثون مريضاً

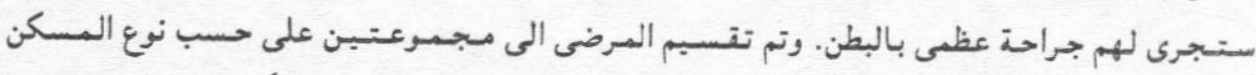

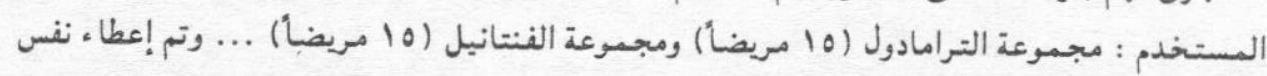

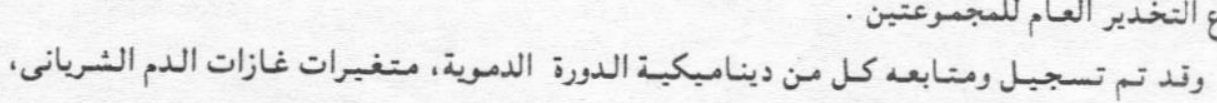

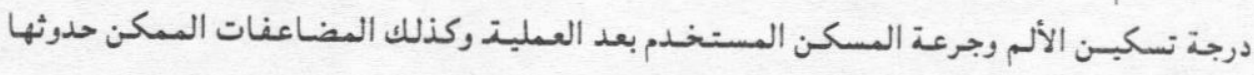
خلال هذه الفترة .

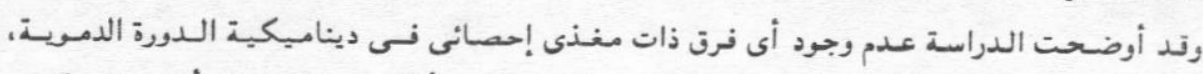

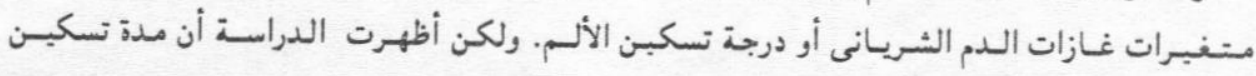

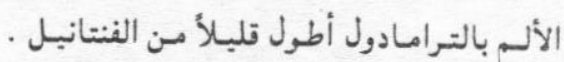

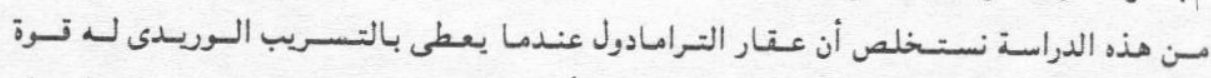

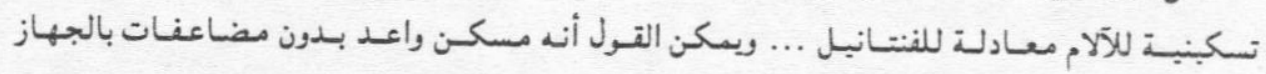

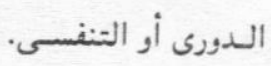


